\title{
Aberrant subclavian artery and Kommerell aneurysm: Surgical treatment with a standard approach
}

Nicholas T. Kouchoukos, MD, and Paolo Masetti, MD

Objective: We report our experience with a standard surgical technique for treatment of aneurysms associated with Kommerell diverticulum and aberrant subclavian artery.

Methods: During a 10-year interval, 10 patients with aneurysms of Kommerell diverticulum and aberrant subclavian artery (8 right, 2 left) underwent surgical repair. All 10 patients had aneurysmal degeneration of the adjacent descending thoracic aorta and 7 had aneurysms of the nonaberrant subclavian artery that required treatment. Four of the patients with large Kommerell aneurysms underwent preliminary carotid-to-aberrant subclavian artery bypass and ligation of the subclavian artery proximal to the origin of the vertebral artery. All patients had graft replacement of the subclavian artery and descending thoracic aneurysms through a left thoracotomy using hypothermic cardiopulmonary bypass and circulatory arrest. Continuity of the aberrant subclavian artery was preserved in the 6 patients without prior carotid-to-subclavian artery bypass.

Results: There were no in-hospital deaths. One patient required reoperation for bleeding, 1 patient developed recurrent laryngeal nerve injury, and 1 patient with delirium had evidence for infarction in the caudate nucleus but recovered completely. There were 4 late deaths from 1.5 to 44 months postoperatively. The remaining 6 patients are well from 8 to 131 months after operation.

Conclusions: Aneurysms of Kommerell diverticulum and coexisting aneurysms of the adjacent descending thoracic aorta and nonaberrant subclavian artery can be repaired safely with the technique we have utilized.

From the Division of Cardiovascular and Thoracic Surgery, Missouri Baptist Medical Center, St Louis, Missouri.

Received for publication Nov 28, 2006; accepted for publication Dec 7, 2006.

Address for reprints: Nicholas T. Kouchoukos, MD, Cardiac, Thoracic and Vascular Surgery, 3009 North Ballas Road, Suite 360 C, St Louis, MO 63131 (E-mail: ntkouch@aol.com).

J Thorac Cardiovasc Surg 2007;133:888-92 $0022-5223 / \$ 32.00$

Copyright () 2007 by The American Association for Thoracic Surgery

doi:10.1016/j.jtcvs.2006.12.005
A berrant subclavian artery is a rare anomaly of the aortic arch. Aneurysms of the origin of these aberrant arteries from the descending thoracic aorta (Kommerell diverticulum) occur in a percentage of patients with either a right aberrant subclavian artery associated with a left-sided aortic arch or a left aberrant subclavian artery associated with a right aortic arch. These aneurysms can cause serious complications, which include distal embolization, compression of adjacent structures, dissection, and rupture. ${ }^{1-3}$ Aneurysms of the adjacent descending thoracic aorta and the nonaberrant subclavian artery may also be present, particularly in older patients.

A number of surgical techniques have been proposed for treatment of these aneurysms. These include transposition or bypass of the distal portion of the aberrant artery into the adjacent carotid artery with or without ligation of the aberrant artery proximally, exclusion of the aneurysmal segment, and resection of the origin of the aneurysm from the descending thoracic aorta. ${ }^{1-3}$ Additional techniques include thoracotomy to replace aneurysmal segments of the descending thoracic aorta with or without use of partial or total cardiopulmonary bypass, hypothermia, and circulatory arrest. ${ }^{2,3}$ Endovascular grafting has also been employed. ${ }^{4}$ 


\section{Abbreviations and Acronyms \\ $\mathrm{CT}=$ computed tomography \\ $\mathrm{IRB}=$ Institutional Review Board}

We present our preferred technique, which involves carotid-to-subclavian artery bypass in selected patients, followed by thoracotomy for repair of the Kommerell diverticulum and associated aneurysms of the adjacent nonaberrant subclavian artery and descending thoracic aorta using hypothermic cardiopulmonary bypass and circulatory arrest.

\section{Patients and Methods \\ Patient Selection}

During a 10-year interval ending in April 2006, 10 patients with aberrant subclavian artery and associated aneurysms of the artery (Kommerell diverticulum) or the adjacent thoracic aorta underwent surgical treatment. This study was reviewed by the Institutional Review Board (IRB) Office of the Missouri Baptist Medical Center, and it was determined that the study was exempt from IRB approval under CFR 46.101 (b)(4). The mean age of the patients was 65 years (range 46-82 years) and 7 were men. Six of the 10 patients presented with chest, back, or shoulder pain, and 1 had paralysis of the left vocal cord. The remaining 3 patients were asymptomatic, and the aneurysms were detected on chest roentgenograms (Figure 1). The maximum diameter of the aneurysms ranged from 3.5 to $7 \mathrm{~cm}$ (mean diameter: $5.8 \mathrm{~cm}$; Figure 2).

The clinical characteristics of the patients are summarized in Table 1. Eight of the 10 patients had a left-sided aortic arch associated with an aberrant right subclavian artery, and 2 had a right-sided aortic arch with an aberrant left subclavian artery. All 10 patients had aneurysms of the aorta adjacent to the origin of the aberrant subclavian artery (Figure 2), and 8 had aneurysms of the aberrant artery (Kommerell diverticulum). Seven of the patients also had aneurysms of the adjacent nonaberrant subclavian artery that required surgical repair. A healed localized tear of the adjacent

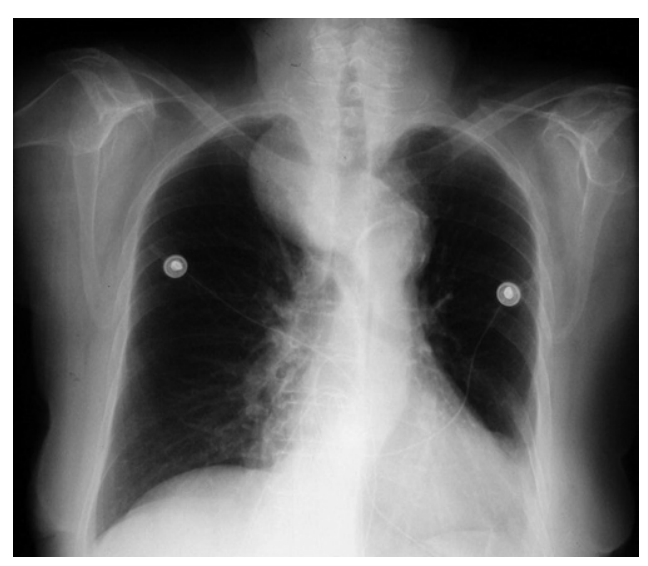

Figure 1. Large aneurysm of Kommerell diverticulum of an aberrant right subclavian artery. The aneurysm involves the entire intrathoracic segment of the aberrant artery.

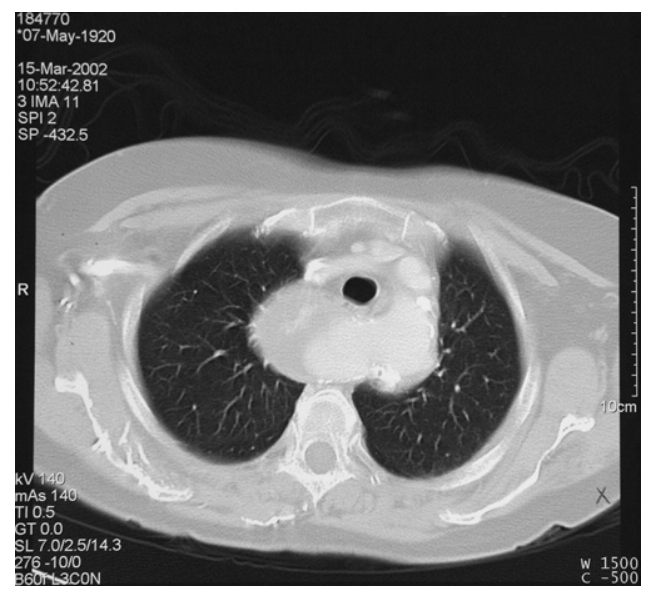

Figure 2. CT image of a large $(5-\mathrm{cm})$ aneurysm of a Kommerell diverticulum associated with an aneurysm $(4.5 \mathrm{~cm})$ of the adjacent descending thoracic aorta. $\mathrm{Cl}$, computed tomography.

aneurysmal aorta was present in 2 patients and a pseudocoarctation of the adjacent aorta in another.

All patients had computed tomography (CT) scans and angiograms of the thoracic aorta performed preoperatively to assess the size and pathway of the aberrant subclavian artery through the mediastinum. These studies were of value in determining whether the operative procedure could be performed entirely through a thoracotomy incision, preserving continuity of the aberrant artery, or whether a carotid-to-subclavian artery bypass grafting procedure would be required prior to the thoracotomy with subsequent exclusion of the aberrant artery.

\section{Operative Technique}

Four of the 10 patients, all with a left-sided aortic arch and an aberrant right subclavian artery, had a right carotid artery-toright subclavian artery bypass graft placed through a right supraclavicular incision immediately prior to thoracotomy. An 8-mm collagen-impregnated polyester graft was used, and the right subclavian artery was ligated proximal to the origin of the right vertebral artery. In all 4 patients, the aberrant subclavian artery was aneurysmal and large (Figure 1), and it was determined that direct continuity between the descending thoracic aorta and the more distal portion of the aberrant artery could not be safely established through the left thoracotomy.

All the aneurysm repairs were performed through a left thoracotomy in the fourth intercostal space using hypothermic cardiopulmonary bypass and an interval of hypothermic circulatory arrest. ${ }^{5}$ The fourth rib was divided posteriorly when necessary to facilitate exposure of the distal aortic arch. The left common femoral artery and vein were used for cannulation. The tip of the venous cannula was positioned in the right atrium. The left heart was vented through the apex of the left ventricle or through the left inferior pulmonary vein. During cooling, the proximal portions of both subclavian arteries and the aneurysmal aorta were dissected free from the surrounding tissues. The left phrenic, vagus, and recurrent laryngeal nerves were identified and protected. 
TABLE 1. Patient characteristics, procedures, and outcomes

\begin{tabular}{|c|c|c|c|c|c|c|c|c|c|c|}
\hline Patient & $\begin{array}{c}\text { Date of } \\
\text { operation }\end{array}$ & $\begin{array}{c}\text { Age } \\
\text { (y) }\end{array}$ & Gender & $\begin{array}{l}\text { Side of } \\
\text { arch }\end{array}$ & $\begin{array}{l}\text { Aneurysm of } \\
\text { aberrant } \\
\text { SCA }\end{array}$ & $\begin{array}{l}\text { Aneurysm of } \\
\text { adjacent } \\
\text { aorta }\end{array}$ & $\begin{array}{l}\text { Aneurysm of } \\
\text { opposite } \\
\text { SCA }\end{array}$ & $\begin{array}{l}\text { Carotid- } \\
\text { subclavian } \\
\text { bypass }\end{array}$ & Procedure & Outcome \\
\hline 2 & $11 / 21 / 1996$ & 50 & $\mathrm{M}$ & $\mathrm{L}$ & 0 & $+^{*}$ & + & 0 & $\begin{array}{l}\text { Replacement distal arch } \\
\text { + DTA, attachment of } \\
\text { ARSA to aortic graft, } \\
\text { 10-mm graft LSA to } \\
\text { aortic graft }\end{array}$ & Alive $111 \mathrm{mo}$ \\
\hline 3 & $7 / 26 / 2000$ & 75 & $M$ & $\mathrm{~L}$ & + & + & + & + & $\begin{array}{l}\text { Replacement distal arch } \\
\text { + DTA, 12-mm graft } \\
\text { ARSA to aortic graft, } \\
\text { 12-mm graft LSA to } \\
\text { aortic graft }\end{array}$ & Alive 66 mo \\
\hline 5 & $5 / 21 / 2002$ & 82 & $\mathrm{~F}$ & $\mathrm{~L}$ & + & + & + & + & $\begin{array}{l}\text { Replacement distal arch } \\
\text { + DTA, ARSA } \\
\text { excluded, 10-mm graft } \\
\text { LSA to aortic graft }\end{array}$ & $\begin{array}{l}\text { Died at } 44 \\
\text { mo } \\
\text { (dementia) }\end{array}$ \\
\hline 6 & $3 / 4 / 2004$ & 62 & $\mathrm{~F}$ & $\mathrm{R}$ & + & + & 0 & 0 & $\begin{array}{l}\text { Patch repair aneurysm, } \\
\text { 8-mm graft ALSA to } \\
\text { onlay patch }\end{array}$ & Alive 27 mo \\
\hline 7 & $1 / 6 / 2005$ & 67 & $\mathrm{~F}$ & $\mathrm{~L}$ & + & + & + & + & $\begin{array}{l}\text { Replacement distal arch } \\
\text { + DTA, ARSA } \\
\text { excluded, 10-mm graft } \\
\text { LSA to aortic graft }\end{array}$ & $\begin{array}{l}\text { Died } 1.5 \text { mo } \\
\text { (MOSF) }\end{array}$ \\
\hline 9 & $1 / 12 / 2006$ & 46 & M & $\mathrm{L}$ & 0 & $+\dagger$ & 0 & 0 & $\begin{array}{c}\text { Replacement distal arch } \\
\text { + DTA, attachment of } \\
\text { ARSA to aortic graft }\end{array}$ & Alive 11 mo \\
\hline 10 & $4 / 7 / 2006$ & 60 & $\mathrm{M}$ & $\mathrm{L}$ & + & + & + & 0 & $\begin{array}{l}\text { Replacement distal arch } \\
\text { + DTA, 12-mm graft } \\
\text { ALSA to aortic graft, } \\
\text { 10-mm graft LSA to } \\
\text { aortic graft }\end{array}$ & Alive $8 \mathrm{mo}$ \\
\hline
\end{tabular}

$A L S A$, aberrant left sublavian artery; $A R S A$, aberrant right subclavian artery; DTA, descending thoracic aorta; $L S A$, left subclavian artery; MOSF, multiple organ system failure; $R S A$, right subclavian artery. *Pseudocoartation; thealed aortic tear.

After establishing circulatory arrest, the aortic aneurysm was incised. In 8 of the 10 patients, the aorta was transected proximally just distal to the origin of the left common carotid artery and distally just below the aortic aneurysm. The segment of diseased aorta was replaced with a collagen-impregnated polyester graft. The aortic aneurysm originated below the origin of the aberrant subclavian artery in 1 additional patient and was replaced with a tube graft. In the remaining patient, the aortic aneurysm was saccular, and it was resected and replaced with a polyester patch. The 7 aneurysms of the nonaberrant subclavian artery were resected and replaced with 10 - or $12-\mathrm{mm}$ collagen-impregnated polyester grafts. These grafts were then anastomosed to the aortic graft. One additional patient had detachment of a normal nonaberrant subclavian artery from the aneurysmal aorta. This artery was directly implanted into the aortic graft. 
TABLE 2. Cardiopulmonary perfusion data

\begin{tabular}{lcl}
\hline Variable & Mean \pm SD & Range \\
\hline Time (min) & & \\
$\quad$ Cardiopulmonary bypass & $101 \pm 16$ & $74-118$ \\
Cooling & $55 \pm 7$ & $24-45$ \\
$\quad$ Circulatory arrest & $36 \pm 9$ & $21-49$ \\
Low flow hypothermic bypass* & $17 \pm 3$ & $13-20$ \\
Hypothermic ventricular fibrillation & $73 \pm 21$ & $50-120$ \\
$\quad$ Rewarming & $54 \pm 9$ & $40-64$ \\
Temperature $\left({ }^{\circ} \mathrm{C}\right)$ & & \\
$\quad$ Lowest nasopharyngeal & $15 \pm 2$ & $13-17$ \\
Lowest bladder/rectal & $19 \pm 3$ & $15-22$ \\
\hline
\end{tabular}

*Five patients.

Among the 8 patients with aneurysms of the aberrant subclavian artery, 4 of the arteries were detached from the adjacent aneurysmal aorta. These 4 patients had large aneurysms and underwent a carotid-to-subclavian artery bypass graft procedure and ligation of the subclavian artery proximal to the origin of the vertebral artery immediately prior to thoracotomy. At thoracotomy, the open, proximal end of the aberrant artery was oversewn with a continuous 4-0 polypropylene suture, thus excluding the aneurysm from the circulation. Of the remaining 4 patients, all of the aneurysm could be excised in 2 of them, and interposition grafts were placed between the distal, normal-sized aberrant artery and the aortic graft. The remaining 2 patients did not have aneurysms of the aberrant artery, and the artery was implanted into a descending thoracic aortic graft in 1 patient and left in continuity with the descending aorta in the other patient. In the 2 patients with a right aortic arch and an aberrant left subclavian artery, access to the aberrant artery and the aneurysmal aorta was possible through the left thoracotomy. The aberrant artery was directly implanted into a descending thoracic aortic graft in 1 patient. In the other, an 8-mm polyester graft was interposed between the aberrant artery and a patch graft on the descending thoracic aorta (Table 1). Rewarming was initiated after completion of the distal graft to aorta anastomosis. Cardiopulmonary bypass was discontinued after completion of rewarming.

The variables related to cardiopulmonary bypass are shown in Table 2. The mean duration of circulatory arrest was 36 minutes. A period of hypothermic low flow to the upper body after attachment of the aortic graft to the proximal aorta was used in 5 patients to minimize the interval of circulatory arrest. This was accomplished with a second arterial line from the pump oxygenator that was attached to a $10-\mathrm{mm}$ side arm of the aortic graft. ${ }^{5}$

\section{Results}

\section{Early}

There were no 30-day or in-hospital deaths. One patient required repeat thoracotomy for bleeding. One patient sustained injury to the left recurrent laryngeal nerve. A third patient was agitated and confused for several days postoperatively without localizing neurologic signs. CT and magnetic resonance imaging studies suggested infarction in the right caudate nucleus. He recovered completely.

\section{Late}

There were 4 late deaths. One patient was readmitted to the hospital for treatment of a left chylothorax and died of multiple system organ failure on the 45 th postoperative day. The other late deaths occurred 9, 22, and 44 months postoperatively of metastatic bladder cancer, lung cancer, and dementia, respectively.

The remaining patients are free of symptoms and abnormal findings on serial CT examinations from 8 to 131 months postoperatively.

\section{Discussion}

Aberrant right subclavian artery occurs in approximately $0.5 \%$ to $1.0 \%$ of the population. ${ }^{6}$ Aberrant left subclavian artery arising from a right aortic arch is less common., Kommerell diverticulum is present in up to $60 \%$ of patients with an aberrant subclavian artery. ${ }^{4}$ Aneurysms of the diverticulum have been observed in $3 \%$ to $8 \%$ of patients with aberrant subclavian artery who have undergone imaging studies. $^{4,7}$

Because of the rarity of the anomaly, the natural history of aneurysms associated with Kommerell diverticulum is not known with certainty. However, rupture and dissection of these aneurysms have been observed. In their review of the literature, Austin and Wolfe reported a rate of rupture of $19 \%$ among 32 patients. ${ }^{1}$ Cinà and colleagues, in a review of patients with aberrant left subclavian artery and right aortic arch, reported a rate of rupture or dissection of $53 \%$ among 32 patients. ${ }^{3}$ We observed evidence of dissection in 2 of our 10 patients.

The size above which surgical intervention should be recommended in asymptomatic or mildly symptomatic patients is not clearly established. Cinà and colleagues recommended surgical treatment for aneurysms $3 \mathrm{~cm}$ or greater in diameter. ${ }^{3}$ Ota and colleagues recommended intervention for symptomatic aneurysms $5 \mathrm{~cm}$ or greater. ${ }^{8}$ Based upon 3 recently reported series, including our own, which have documented the safety of elective operative intervention (no deaths among a total of 24 patients), early intervention appears appropriate. ${ }^{8,9}$

A number of surgical approaches have been utilized. We employed a relatively standardized approach: a carotid-tosubclavian artery bypass in patients where direct continuity between the descending thoracic aorta and the distal subclavian artery could not be easily established, left thoracotomy in all patients with resection and graft replacement of the Kommerell aneurysm when present, as well as replacement of aneurysms of the adjacent descending thoracic aorta and opposite subclavian artery. This approach provided satisfactory exposure of the proximal portion of the aberrant artery, the distal aortic arch, and the descending thoracic aorta. This was true even for the 2 patients with aberrant left subclavian artery and right aortic arch. Of interest, aneu- 
rysms of the adjacent thoracic aorta were present in all of our patients and of the nonaberrant subclavian artery in 7 of them. This may reflect the older age (mean 65 years) of our patients. Other reports have also included patients with large aneurysms and dissections of the descending thoracic aorta that required concomitant treatment. ${ }^{9-11}$ Based upon our experience and the recently reported experience of others ${ }^{8,9}$ employing selective carotid-to-subclavian artery bypass, thoracotomy, and cardiopulmonary bypass with or without use of hypothermic circulatory arrest, we believe this represents the optimal method of management of patients with this anomaly. In our experience, use of hypothermic circulatory arrest eliminated the need for clamping of the aortic arch, the descending thoracic aorta, and the aberrant and opposite subclavian arteries; greatly facilitated exposure, particularly of the aberrant artery in the mediastinum; and was not associated with adverse outcomes. It remains our preferred method of treatment.

\section{References}

1. Austin EH, Wolfe WG. Aneurysm of aberrant subclavian artery with a review of the literature. J Vasc Surg. 1985;2:571-7.

2. Kieffer E, Bahnini A, Koskas F. Aberrant subclavian artery: surgical treatment in thirty-three adult patients. J Vasc Surg. 1994;19:100-11.
3. Cinà CS, Althani H, Pasenau J, Abouzahr L. Kommerell diverticulum and right-sided aortic arch: a cohort study and review of the literature. J Vasc Surg. 2004;39:131-9.

4. Davidian M, Kee ST, Kato N, Semba CP, Razavi MK, Mitchell RS, et al. Aneurysm of an aberrant right subclavian artery: treatment with PTFE covered stentgraft. J Vasc Surg. 1998;28:335-9.

5. Kouchoukos NT, Masetti P, Rokkas CK, Murphy SF, Blackstone EH. Safety and efficacy of hypothermic cardiopulmonary bypass and circulatory arrest for operations on the descending thoracic and thoracoabdominal aorta. Ann Thorac Surg. 2001;72:699-708.

6. Freed K, Low VH. The aberrant subclavian artery. AJR Am J Roentgenol. 1997;168:481-4.

7. Branscom JJ, Austin JHM. Aberrant right subclavian artery: findings seen on plain chest roentgenograms. AJR Am J Roentgenol. 1973;119: $539-42$.

8. Ota T, Okada K, Takanashi S, Yamamoto S, Okita Y. Surgical treatment for Kommerell diverticulum. J Thorac Cardiovasc Surg. 2006; 131:574-8.

9. Kamiya H, Knobloch K, Lotz J, Bog A, Lichtenberg A, Hagl C, et al. Surgical treatment of aberrant right subclavian artery (arteria lusoria) aneurysm using three different methods. Ann Thorac Surg. 2006;82: $187-90$.

10. Stone WM, Brewster DC, Moncure AC, Franklin DP, Cambria RP, Abbott WM. Aberrant right subclavian artery: varied presentations and management options. J Vasc Surg. 1990;11:812-7.

11. Caus T, Gaubert JY, Monties JR, Moulin G, Mouly A, Cornen A, et al. Right-sided aortic arch: surgical treatment of an aneurysm arising from a Kommerell diverticulum and extending to the descending thoracic aorta with an aberrant left subclavian artery. Cardiovascular Surgery. 1994;2:110-3. 